\title{
Gestão do cuidado de estudantes com necessidades alimentares especiais vinculados ao Programa Nacional de Alimentação Escolar
}

\author{
I ${ }^{1}$ Silviani da Silva Colares, ${ }^{2}$ Fabiane Ferraz, ${ }^{3}$ Ingrid Dalira Schweigert Perry, \\ ${ }^{4}$ Jacks Soratto I
}

Resumo: O estudo objetiva analisar os mecanismos de gestão do cuidado voltados aos estudantes com necessidades alimentares especiais (NAE) vinculados às Secretarias Municipais de Educação do Estado de Santa Catarina. Tratase de estudo de métodos mistos, com estratégia incorporada concomitante, realizado com 134 nutricionistas que prestam assistência a estudantes com NAE. Utilizou-se questionário enviado por correio eletrônico como instrumento de coleta de dados, que foi avaliado por meio da análise de conteúdo temática e por estatística descritiva. Os resultados indicaram que o atestado ou laudo médico para oferta da alimentaçáo especial foram os principais documentos comprobatórios; a licitação tipo pregão foi o meio de obtenção de alimentos especiais; os manipuladores de alimentos predominaram no recebimento de orientação referente às NAE; falta de produtos e fornecedores foram indicados como dificuldades; $\mathrm{e}$ garantia de atendimento destacada como facilidade na gestão das NAE. Quanto às características da gestão, destacam-se a ausência de solicitação de ficha técnica $(79,9 \%)$, de oferta de alimentação especial (62\%), de material informativo (92,5\%) e da disponibilização de utensílios (63,4\%). A assistência nutricional nos municípios catarinenses possui mecanismos de gestão diversos, que atendem às necessidades dos estudantes com NAE, mas ainda possui algumas fragilidades que dificultam a efetivação da assistência integral.

> Palavras-chave: gestão em saúde; programas e políticas de nutrição e alimentação; alimentação escolar.

\author{
1 Universidade do Extremo Sul \\ Catarinense (Unesc). Criciúma-SC, \\ Brasil (silvianicolares@hotmail.com). \\ ORCID: 0000-0001-7100-9801 \\ ${ }^{2}$ Universidade do Extremo Sul \\ Catarinense (Unesc). Criciúma- \\ SC,Brasil (olaferraz@gmail.com). \\ ORCID: 0000-0003-1782-6784 \\ ${ }^{3}$ Centro de Estudos em \\ Alimentação e Nutrição, \\ Universidade Federal do Rio Grande \\ do Sul (UFRGS). Porto Alegre-RS, \\ Brasil (atputp@gmail.com). \\ ORCID: 0000-0002-7836-5857 \\ ${ }^{4}$ Programa de Pós-graduação em \\ Saúde Coletiva, Universidade do \\ Extremo Sul Catarinense (Unesc). \\ Criciúma-SC, Brasil (jackssoratto@ \\ hotmail.com). \\ ORCID: 0000-0002-1339-7268
}

Recebido em: 31/03/2020 Aprovado em: 31/07/2020 Revisado em: 09/10/2020 


\section{Introdução}

O campo da alimentaçáo escolar no Brasil passou por diversas mudanças no decorrer dos anos, deixando de focar exclusivamente no estado de fome para melhorar o atendimento dos estudantes no período letivo como um todo (CESAR et al., 2018). Para tanto, foram adotadas medidas que possibilitam a formação de hábitos alimentares saudáveis e ofereçam um aporte nutricional adequado à realização de atividades, sem comprometer o estado de saúde, crescimento, desenvolvimento e aprendizagem dos estudantes (BRASIL, 2020; BRASIL, 2009).

Ao longo da história, a Organização das Naçóes Unidas (ONU) busca estabelecer estratégias de políticas nutricionais e de combate à fome que sejam adotadas em todos os países. Contudo, para assegurar o direito humano à alimentação adequada (DHAA), há necessidade de o Estado garantir um acesso à alimentação que considere os aspectos físicos, econômicos e/ou por meio de políticas públicas de maneira contínua (ONU, 1999).

Entre as políticas públicas voltadas à garantia do DHAA no Brasil, destacase a Política Nacional de Alimentação e Nutrição, a qual proporciona, mediante seu conjunto de programas, a melhora das condições de alimentação, nutrição e, consequentemente, saúde da população (BRASIL, 2013a). Nesse contexto, o setor de educaçáo compromete-se com o DHAA ao implantar e efetivar o Programa Nacional de Alimentação Escolar (PNAE), instituído na Lei no 11.947 de 2009, conhecida como Lei da Merenda Escolar (BRASIL, 2009).

A partir da implantação do PNAE, algo que se destacou na última década foi o considerável aumento do número de estudantes com necessidades alimentares especiais (NAE). No âmbito escolar, as principais doenças relacionadas às NAE são descritas no manual de orientação sobre a alimentação escolar para pessoas com doenças específicas do ano de 2012 (VASCONCELOS et al., 2012), no caderno de referência sobre alimentação escolar para estudantes com NAE (BRASIL, 2017) e na resolução no 6 de 8 de maio de 2020 (BRASIL, 2020). Dentre as NAE existentes, é importante destacar diabetes mellitus (DM); hipertensão arterial sistêmica (HAS); doença celíaca (DC); fenilcetonúria (PKU); intolerâncias alimentares, especialmente à lactose; (IL) e alergias alimentares (AA), além das anemias (BRASIL, 2020; BRASIL, 2017; VASCONCELOS et al., 2012). 
Essas condiçôes de saúde no setor de educação muitas vezes exigem um maior envolvimento e preparo de diversos setores e profissionais, para que o atendimento a esses estudantes seja realizado universal e integralmente e o direito à alimentação adequada seja assegurado. Assim sendo, o presente estudo procura responder à seguinte questáo de pesquisa: quais os mecanismos de gestão do cuidado voltados aos estudantes com necessidades alimentares especiais vinculados às Secretarias Municipais de Educação do Estado de Santa Catarina, na perspectiva dos nutricionistas que atuam no PNAE? Diante do exposto, ao evidenciar a necessidade de atendimento integral à saúde dos estudantes com NAE, o objetivo deste estudo foi analisar os mecanismos de gestáo do cuidado voltados aos estudantes com necessidades alimentares especiais (NAE) vinculados às Secretarias Municipais de Educação do Estado de Santa Catarina.

\section{Métodos}

A presente pesquisa é um estudo de métodos mistos, com uma estratégiaincorporada concomitante (CRESWELL, 2010; SANTOS et al., 2017), com característica exploratória e descritiva. O estudo foi aprovado pelo Comitê de Ética em Pesquisa da Universidade do Extremo Sul Catarinense (CAAE: 91936718.8.0000.0119; Parecer $\mathrm{n}^{\circ}$ 2.744.896). A pesquisa foi desenvolvida junto aos nutricionistas das Secretarias Municipais de Educação (SME) do Estado de Santa Catarina, Brasil.

Quanto à seleção dos participantes, foram recrutados aqueles aos quais o pesquisador teve acesso e que prestavam assistência a estudantes com NAE, sendo que de 295 nutricionistas vinculados às SMEs do Estado de Santa Catarina, somente 134 participaram do estudo. Dos participantes investigados, predominaram o sexo feminino $(98,5 \%$ - $\mathrm{n}=132)$, idade entre 30 e 34 anos $(39,6 \%$ $\mathrm{n}=53)$. Quanto ao nível de escolaridade do grupo, caracterizou-se por apresentar algum tipo de especialização $(74,6 \%-n=100)$ e o mestrado $(3 \%-n=4)$. O tempo de atuação profissional como nutricionista apresentou um maior grupo entre 7 a 9 anos $(28,3 \%-n=38)$, e alguns profissionais $(2,2 \%-n=3)$ atuam há menos de um ano. Já no tempo de atuação profissional como responsável pelo PNAE no município, destacaram-se os grupos correspondentes a 1 e 3 anos de atuação $(35 \%-n=47)$ e acima de 19 anos $(1,5 \%-n=2)$.

Ao considerar a distribuição de nutricionistas de acordo com o vínculo empregatício, destacaram-se o percentual de profissionais concursados $(83,6 \%$ - 
$\mathrm{n}=112)$, carga horária de 40 horas semanais $(47 \%-\mathrm{n}=63)$ e dedicação exclusiva à SME $(65 \%-n=87)$. A responsabilidade técnica da alimentação escolar destinada a um único nutricionista representou $97,8 \%(\mathrm{n}=131)$ deste estudo.

O instrumento para coleta de dados foi um questionário (Google forms), composto de perguntas fechadas e abertas, elaborado pelos pesquisadores e enviado via correio eletrônico (e-mail) para o endereço oficial da SME por três vezes. Ao abrir o link, o participante visualizava o Termo de Consentimento Livre e Esclarecido na íntegra, opção de participar ou não da pesquisa. Após aceite, o participante era direcionado para as perguntas, tendo a oportunidade de preencher em uma única vez o formulário. As respostas dos participantes foram recebidas entre 06 agosto e 06 setembro 2018. Houve alta taxa de não resposta, que pode estar associada a desinteresse em participar da pesquisa, possíveis falhas na visualização e ou ausência na prestação da assistência a estudantes com NAE no âmbito municipal.

Os dados qualitativos foram analisados por meio da análise de conteúdo, com temática estruturada em três fases: a) pré-análise: organização dos achados e inserção dos questionários (documents) no Atlas.ti; b) exploração do material: definição das expressóes significativas das respostas (quotations) e a codificação (codes) e agrupamento em cinco categorias (group codes); e c) tratamento dos resultados obtidos e interpretação: integração entre os trechos de respostas, códigos e grupos de códigos e criação de rede categorial (network) (SORATTO; PIRES; FRIESE, 2020). Por sua vez, os dados quantitativos foram analisados por estatística descritiva de maneira complementar, e incorporados aos achados qualitativos.

Para apresentação dos dados, foram utilizadas frequências absoluta (n) e relativa (\%), rede categorial (network), e recortes dos trechos de respostas mais significativas do questionário. A perspectiva teórica adotada para discussão dos achados está embasada nos pressupostos das normativas governamentais que balizam a alimentação para estudantes (BRASIL, 2009; 2014; 2017).

\section{Resultados e Discussão}

Os resultados estruturaram-se a partir de seis blocos analíticos, sendo cinco provenientes da análise qualitativa e um da análise quantitativa, conforme a figura a seguir. 
Figura 1. Descrição dos blocos analíticos do estudo

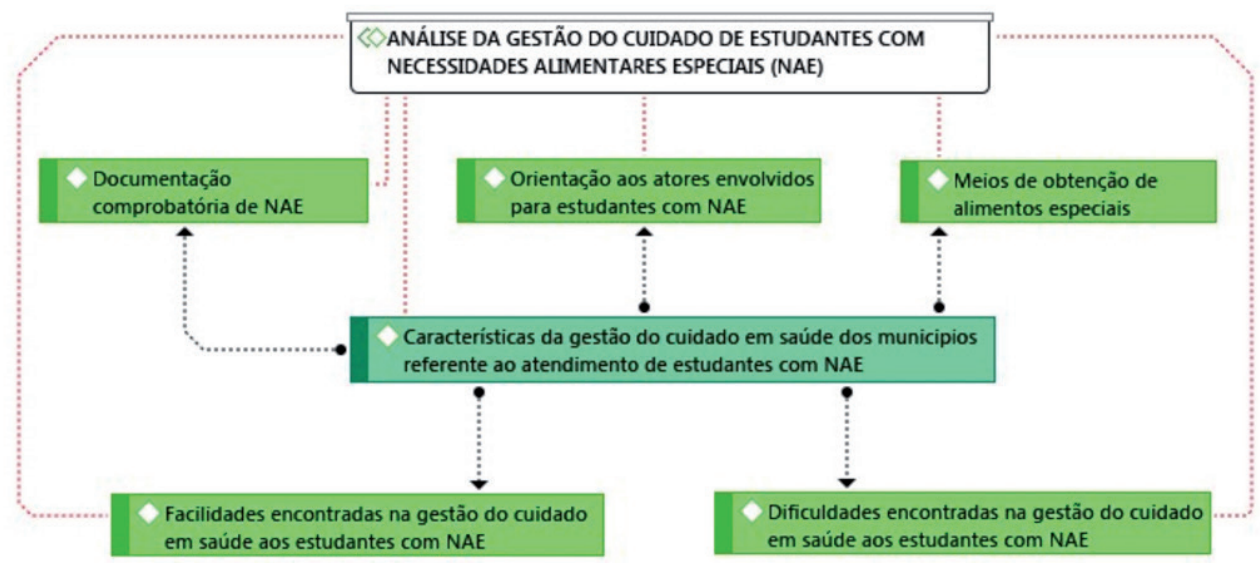

*NAE: Necessidades Alimentares Especiais.

Fonte: elaboração própria.

O achado qualitativo gerou um banco de dados composto por 399 trechos de respostas e 20 códigos, estes vinculados a cinco blocos analíticos, conforme descrito na tabela a seguir.

Tabela 1. Relação do número de trechos de respostas selecionadas com os códigos e subcategorias vinculadas à gestáo do cuidado destinado ao atendimento de estudantes com NAE. Santa Catarina, 2018

\begin{tabular}{llcc}
\hline \multirow{2}{*}{ Categoria } & Códigos & \multicolumn{2}{c}{ Trechos } \\
& & $\mathrm{N}$ & $\%$ \\
\hline $\begin{array}{l}\text { Documentaçáo } \\
\text { comprobatória de NAE }\end{array}$ & Atestado médico & 92 & 23,0 \\
& Atestado médico e exames laboratoriais & 14 & 3,5 \\
Meios de obtenção de & Licitação & 31 & 7,7 \\
alimentos especiais & Compra direta & 15 & 3,8 \\
& Acordos & 11 & 2,8 \\
Orientação aos atores & Manipuladores de alimentos & & \\
envolvidos com os estudantes & Pais ou responsáveis & 27 & 6,8 \\
com NAE & Direção escolar e professores & 11 & 2,8 \\
& & 8 & 2,0
\end{tabular}




\begin{tabular}{llcc}
\hline \multirow{2}{*}{ Categoria } & Códigos & \multicolumn{2}{c}{ Trechos } \\
& & $\mathrm{N}$ & $\%$ \\
\hline & Falta de produtos e/ou fornecedores & 22 & 5,5 \\
& Ausência de laudo médico e/ou exames & 19 & 4,8 \\
Dificuldades encontradas & Setor de compras/licitação & 15 & 3,8 \\
na gestão do cuidado para & Recurso humano e estrutura física & 12 & 3,0 \\
a assistência aos estudantes & Comunicação falha & 11 & 2,8 \\
com NAE & Descumprimento das orientações & 10 & 2,5 \\
& Baixa aceitação & 8 & 2,0 \\
& & & \\
Facilidades encontradas & Garante o atendimento & 31 & 7,7 \\
na gestão do cuidado na & Boa/sem dificuldades & 26 & 6,5 \\
assistência destinada aos & Setor de compras & 15 & 3,8 \\
estudantes com NAE & Compreensão da lei & 12 & 3,0 \\
Total & Autonomia atribuída ao nutricionista & 9 & 2,2 \\
\hline
\end{tabular}

Fonte: Banco de dados da pesquisa, 2018.

*NAE: Necessidades Alimentares Especiais.

Por sua vez, o outro bloco analítico contemplou os aspectos relacionados às características da gestão dos municípios, referentes ao atendimento dos estudantes com NAE no âmbito do PNAE, que estão descritos na tabela a seguir.

Tabela 2. Características da gestão dos municípios referentes ao atendimento de estudantes com NAE no âmbito do PNAE. Santa Catarina, 2018

\begin{tabular}{lcc}
\multicolumn{1}{c}{ Variáveis } & $\mathrm{n}$ & $\%$ \\
\hline Gestão dos recursos do PNAE (n=134) & & \\
Centralizada & 130 & 97,1 \\
Semidescentralizada ou mista & 1 & 0,7 \\
Terceirizada & 3 & 2,2 \\
Modalidade de licitação (n=134) & & \\
Pregão & 81 & 60,4 \\
Pregão de sistema de registro de preço (SRP) & 31 & 23,1 \\
Não houve procedimento específico & 12 & 9,0 \\
Compra direta com dispensa de licitação & 8 & 6,0 \\
Náo sabe & 2 & 1,5 \\
& & continua...
\end{tabular}


Variáveis

Não

Sim

Oferta de alimentação especial a todas as NAE ( $\mathrm{n}=134)$

Não

Sim

Como ocorre em caso de não oferta de alimentação especial (n=83)

Os pais/responsáveis pelo estudante enviam a alimentação

A instituição de ensino oferta a alimentação especial

Não sabe

Motivos do não amparo aos estudantes com NAE $(\mathrm{n}=83)$

Indisponibilidade de fornecedores/produtos

Alto custo dos produtos

Desconhecimento e inaptidão da gestão no atendimento da NAE

Não sabe

Dispóem de página on-line para solicitação e divulgação da NAE (n=134)

Não

Sim

Presença de material informativo no mural da escola $(n=134)$

Não

Sim

Disponibilização de utensílios e equipamentos ( $\mathrm{n}=134)$

Não

Sim

Não é necessária a utilização de utensílios

Documentação exigida para oferta de alimentação especial (n=134)

Laudo médico

Laudo médico e exames laboratoriais

Declaração dos pais/responsáveis alegando que o estudante apresenta

NAE e laudo médico e exames laboratoriais

Exames laboratoriais

$1 \quad 0,7$

Não é exigida documentação

Periodicidade de atualização de documentação (n=134)

Atualizado 1 vez por ano

$\begin{array}{cc}108 & 80,6 \\ 16 & 11,9 \\ 7 & 5,3 \\ 2 & 1,5 \\ 1 & 0,7\end{array}$

É exigido 1 única vez

É atualizado a cada 6 meses

Não é atualizado

Não se aplica 


\begin{tabular}{|c|c|c|}
\hline Variáveis & $\mathrm{n}$ & $\%$ \\
\hline \multicolumn{3}{|c|}{ Declaração de compromisso dos pais/responsáveis $(\mathrm{n}=134)$} \\
\hline Não & 76 & 56,7 \\
\hline Sim & 58 & 43,3 \\
\hline \multicolumn{3}{|c|}{ Declaração de cancelamento da alimentação especial ( $\mathrm{n}=134)$} \\
\hline Não & 119 & 88,8 \\
\hline Sim & 15 & 11,2 \\
\hline \multicolumn{3}{|c|}{$\begin{array}{l}\text { Orientação destinada aos diretores/coordenadores e professores } \\
\text { sobre NAE }(n=134)\end{array}$} \\
\hline Não & 38 & 28,4 \\
\hline Sim & 96 & 71,6 \\
\hline \multicolumn{3}{|c|}{ Capacitação dos manipuladores de alimentos quanto à NAE (n=134) } \\
\hline Não & 30 & 22,4 \\
\hline Sim & 104 & 77,6 \\
\hline \multicolumn{3}{|c|}{$\begin{array}{l}\text { Presença de documentaçáo que comprove a capacitação dos manipuladores } \\
\text { de alimentos ( } \mathrm{n}=104)\end{array}$} \\
\hline Não & 55 & 52,9 \\
\hline Sim & 49 & 47,1 \\
\hline
\end{tabular}

Fonte: Banco de dados da pesquisa. 2018.

*NAE: Necessidades alimentares especiais. PNAE: Programa Nacional de Alimentação Escolar.

\section{Documentação comprobatória de necessidades alimentares especiais}

O documento comprobatório de NAE, representado pelo laudo médico, é demonstrado por meio dos trechos de respostas em que os participantes relataram que a apresentação de laudo médico para a comprovaçáo é considerada um aspecto decisivo para a decisão da gestão quanto à oferta da alimentação especial, a seguir:

Uma dificuldade que encontrávamos nos anos anteriores era a questão de que qualquer problema que a criança apresentava em relação à alimentação, os pais já "suspeitavam" que era intolerância à lactose ou alguma alergia alimentar, e logo queriam que as escolas adaptassem a alimentação da mesma. Em função dessas situaçôes começamos a exigir no momento da matrícula da criança o atestado, caso existisse realmente algum problema. A partir disso, reduziram mais da metade das solicitaçóes para adaptações e, dessa forma, conseguimos fazer um acompanhamento melhor para essas crianças que realmente apresentam alguma necessidade especial [P126].

Esse dado corroborou o apontado por $81,4 \%(n=109)$ dos participantes, os quais consideram o atestado (laudo médico) requisito fundamental para se garantir o direito à alimentação especial aos estudantes com NAE. A apresentação de um documento 
específico à SME quando os pais ou responsáveis assumem a responsabilidade pela alimentaçáo especial escolar foi demonstrada por 43,3\% $(n=58)$ dos participantes.

Entre as formas de identificação, pode-se citar a exigência de um documento comprobatório como o laudo médico (BRASIL, 2017) e/ou exame laboratorial, entre outros. Estes documentos, quando apresentados ao serviço de alimentação escolar, permitem ao nutricionista do PNAE o planejamento das compras da alimentação especial, assim como a determinação da conduta adequada às NAE (COLARES; SORATTO, 2019).Ao considerar a apresentação de um único documento (laudo/ atestado médico) para comprovar as NAE do estudante, estas podem se tornar vagas, pois, como foram relatados por alguns participantes, muitos pais ou responsáveis entram em um consenso com o profissional responsável pela prescrição do documento, por acharem conveniente a oferta de determinado alimento ou simplesmente não apresentarem o laudo pelo fato de o estudante não ter NAE.

Nesta situação, a solicitação de exames laboratoriais, juntamente com o atestado médico, aos pais ou responsáveis pelo estudante auxiliará na tomada de decisão do nutricionista do PNAE quanto à oferta da alimentação especial, bem como facilitará o atendimento aos estudantes que realmente precisam e permitirá analisar se a prescrição no atestado médico está condizente com as NAE apresentadas, segundo o trecho de fala a seguir:

Os estudantes que têm alguma alergia ou intolerância alimentar devem obrigatoriamente apresentar atestado médico e parecer com exame (em caso de alergias e intolerâncias) para que a compra de alimentos especiais seja realizada e posteriormente disponibilizada para sua alimentação [P94].

A importância da solicitação dos exames laboratoriais, juntamente com o laudo/ atestado médico, fundamenta-se pela característica apresentada por algumas NAE, como a intolerância à lactose e a alergia alimentar, as quais podem não apresentar sintomas permanentes e são possivelmente reversíveis quando tratadas de maneira correta (MATTAR; MAZZO, 2010), bem como devido à prescrição inadequada ou incompleta de atestados médicos.

Embora as respostas dos participantes não tenham citado a periodicidade de atualização dos documentos comprobatórios de NAE, 80,6\% (n=108) relataram que solicitam a atualização deste tipo de documento comprobatório uma vez por ano e $5,3 \%(\mathrm{n}=7)$ solicitam a cada seis meses. Acredita-se que a postura dos nutricionistas em relaçáo a essa questáo deve-se ao fato de que o caderno de referência sobre a 
alimentação escolar para estudantes com NAE orienta que o cardápio especial elaborado pelo nutricionista deve ser ofertado mediante a apresentaçáo de uma declaração recente de um profissional de saúde. Na impossibilidade de apresentação de um documento completo, o profissional responsável deve observar a completude das informaçôes, buscando dados adicionais para conhecer a real condição de saúde de estudante. Destaca-se que as orientaçóes contidas nesse caderno de referência não se propóem a delimitar estritamente a forma na qual o atendimento deve ser realizado (BRASIL, 2017).

É importante ponderar que, ao determinar que seja solicitada a documentação comprobatória de NAE por meio de uma declaração recente de um profissional de saúde, pode-se também gerar algumas situações que impedem o acesso à alimentação adequada por parte desses estudantes, tais como: tornar excludente a oferta de alimentação escolar a quem mais necessita dela; o estudante pode não conseguir apresentar a documentação, pois a mesma pode estar ainda com um diagnóstico não conclusivo, ou em fase de análise pelo médico; e, principalmente, por não haver amparo legal para negar alimento específico.

Sobre essa discussão, é importante destacar que, segundo a Lei 12.982 de 2014, o cardápio especial deve ser elaborado com base nas recomendações médicas e nutricionais, avaliação nutricional e demandas nutricionais diferenciadas (BRASIL, 2014). Não está estabelecida na legislação, portanto, a apresentação de um documento comprobatório de NAE, assim como a periodicidade de atualizaçáo de tal documento.

Há que considerar que os diferentes modelos de gestão e articulação existentes, aliados às dimensôes e aspectos socioculturais, permitem diferentes realidades nesse campo em todo o país. Cada um desses espaços deve igualmente acolher estudantes com atestados médicos e laudos oriundos de diferentes esferas da saúde pública e da saúde suplementar (BRASIL, 2017); contudo, não deveria excluir quem ainda não possui tais documentos.

Colares e Soratto (2019), ao desenvolverem os itinerários para atenção integral aos estudantes com necessidades alimentares especiais, sugerem a apresentação de outros documentos por parte dos pais ou responsáveis pelos estudantes com NAE à gestão escolar, especialmente aos nutricionistas do PNAE, como a declaração de solicitação da alimentação especial, declaração de compromisso e declaração de cancelamento da alimentação especial. Entretanto, deve-se atentar para que esse tipo 
de "olhar" dos profissionais envolvidos, assim como as sugestôes das documentaçôes recomendadas, não sirva de impedimento para a inclusão do estudante com NAE ao acesso à atenção nutricional adequada, evitando qualquer tipo de agravo à saúde ou constrangimento dos estudantes ou a suas famílias.

Sendo assim, a partir da determinação ou não dos documentos que serão apresentados pelos pais ou responsáveis à gestão municipal para que os estudantes tenham acesso à alimentação especial (COLARES, SORATTO, 2019), é dever do nutricionista orientar toda a comunidade escolar sobre a importância de uma alimentação especial adequada, procedimentos, benefícios, riscos e demais cuidados referentes à condição de saúde (BRASIL, 2018) apresentada pelo estudante.

Ressalta-se que, embora seja importante que haja a organização da gestão do cuidado em saúde no âmbito municipal, reforça-se que a mesma, ao estabelecer a tomada de decisão, deve assegurar o DHAA dos estudantes.

\section{Meios de obtenção de alimentos especiais}

Esta categoria expressa como a gestão municipal se organiza para realizar a aquisição dos gêneros alimentícios destinados aos estudantes com NAE.

O modelo de gestão do PNAE apontado pela maioria $(97,1 \%-n=130)$ dos participantes é na modalidade centralizada. A predominância da gestão centralizada dos recursos do PNAE nos municípios catarinenses pode ser justificada por proporcionar maior proximidade da entidade executora com os produtos a serem ofertados na alimentação escolar, melhor gestão dos recursos, supervisão e avaliação da alimentação escolar (CORREA et al., 2017), assim como nas demais etapas necessárias ao serviço, tornando esta modalidade a mais utilizada entre os municípios catarinenses estudados e provavelmente entre municípios brasileiros.

Para a realização da aquisição dos alimentos especiais, a utilização da modalidade de licitaçáo foi identificada nos trechos de respostas da maior parte dos participantes como o principal meio da gestão municipal para obter e assegurar a oferta da alimentação especial aos estudantes:

A cada nova licitaçáo, buscamos obter novos alimentos e ingredientes, que são requeridos (e que ainda não tínhamos comprado) para tentar, ao máximo, integrar a alimentação das crianças que necessitam de alimentaçáo especial [P107].

Todos os alimentos para as necessidades alimentares específicas são adquiridos através de licitaçáo, realizamos registro de preços, e funciona bem [P61]. 
Tal dado também foi apontado por 60,4\% $(\mathrm{n}=81)$ dos participantes ao relatarem a modalidade de licitação por meio de pregão como o meio de obtenção mais utilizado para a aquisição dos alimentos especiais.

Quanto à aquisição dos gêneros alimentícios, a modalidade de licitação através do pregão permite a aquisição de bens e serviços, podendo ser aplicada a qualquer valor estimado de contratação. Leva em consideração para a classificação e habilitação o licitante que apresentar a proposta com menor preço, sendo este o critério de julgamento (BRASIL, 2002). Os participantes do estudo expressam a dificuldade de estar adquirindo os alimentos especiais após a realização do procedimento licitatório, pois a licitação em exercício muitas vezes impossibilita o atendimento de novos casos de NAE no decorrer do ano letivo, devido à impossibilidade de estimar o número de estudantes que necessitam desse tipo de alimentação e, consequentemente, a quantidade dos produtos.

O caderno de referência para alimentação escolar de 2017 expressa que o pregão por sistema de registro de preço é o procedimento adequado na contratação futura de alimentos especiais ao atual cenário das NAE no âmbito do PNAE (BRASIL, 2017). Nesse procedimento, o fornecedor deve estar apto por meio de processo licitatório específico e assumir a responsabilidade de fornecer os alimentos especiais, conforme a necessidade da administração pública e outras condições estabelecidas em edital, pelo prazo máximo de um ano no valor que está registrado (podendo este ser corrigido ou não) sem a obrigatoriedade de contrataçáo (BRASIL, 2013b).

Outro aspecto importante a ser considerado no momento da elaboração do edital de licitação é a solicitação da apresentação de ficha técnica do produto para assegurar que o mesmo atenda às NAE e, principalmente, não ofereça risco ao estudante.

A maioria dos participantes da presente pesquisa 79,9\% ( $\mathrm{n}=107)$ não solicita a apresentação de ficha técnica do produto especial no momento da licitação. Caso esta conduta não seja de fácil realização, a RDC no 26 de 2015 estabelece a rotulagem obrigatória de alérgenos (BRASIL, 2015). Desta forma, recomenda-se ao nutricionista do PNAE estar atento aos rótulos dos produtos e, se necessário, entrar em contato com o serviço de atendimento ao cliente dos fabricantes (BRASIL, 2017).

A contratação direta com dispensa de licitação, popularmente conhecida como compra direta, ocorre entre a administração pública e o interessado sem o procedimento licitatório prévio, onde sua realização pode ser justificada em razão do valor do item, assim como, para a aquisição de gêneros perecíveis, tornando-se um 
meio viável no atendimento das necessidades especiais até que o processo licitatório esteja apto a ser realizado, pois não requer planejamento e acarreta menos tempo para sua execução (BRASIL, 1993).

Outro dado apontado nesse estudo é a ausência de um procedimento específico para a aquisição da alimentação especial, que foi associado ao código "acordos", no qual os participantes apontaram em suas respostas a realização de um acordo da SME com os pais ou responsáveis para a oferta de alimentação especial, conforme o trecho a seguir:

São realizadas adaptaçóes nos cardápios (quando ainda não existe nenhum caso igual), e as compras são adequadas a esta necessidade. Caso tais produtos não sejam licitados, é realizada uma compra direta ou entra-se em acordo com pais ou responsáveis para o fornecimento de algum produto [P38].

A ausência de um procedimento específico para a aquisição da alimentação especial foi apresentada por $9 \%(\mathrm{n}=12)$ dos participantes. E nos munícipios onde a alimentação especial não é ofertada a todos os estudantes com NAE $(62 \% ; n=83)$, $50 \%(\mathrm{n}=67)$ desses participantes relataram que a alimentação especial é oferecida pelos pais ou responsáveis pelos estudantes.

Além dos tipos legais de aquisição de alimentos especiais, a realização de um acordo entre a SME e os pais ou responsáveis ao mesmo tempo foi apontada como um procedimento de garantia da alimentação especial. Este acordo muitas vezes pode ser estabelecido até que a licitação ou processo de compra direta seja realizado, e como uma forma de precaução dos pais ou responsáveis quanto ao risco de contaminação cruzada, garantindo a oferta de uma alimentação segura.

Quanto à disponibilidade de alguma declaração ou documento destinado aos pais ou responsáveis na SME, em que os mesmos se comprometem com a alimentação escolar do seu filho, 56,7\% (n=76) dos participantes relataram que náo há esse tipo de documentação comprobatória. Este resultado também é relacionado ao código "acordos" como um meio de obtenção de alimentação especial. Porém, a maior parte dos participantes não documenta esta responsabilidade quando atribuída aos pais ou responsáveis, e esta medida pode gerar complicações na realizaçáo do trabalho do nutricionista, caso ocorra algum imprevisto, ou algum dano à saúde do estudante.

Embora a responsabilidade técnica assumida pelo nutricionista do PNAE esteja envolvida nas mais diferentes etapas da segurança alimentar e nutricional (BRASIL, 2009), é importante o nutricionista assegurar, por meio de um 
documento específico, o comprometimento dos pais ou responsáveis em ofertar a alimentação do estudante no período escolar (COLARES; SORATTO, 2019). Ressalta-se que antes de solicitar aos pais ou responsáveis a assinatura deste termo de responsabilidade, é extremamente necessário orientá-los quanto à importância, à qualidade e às formas de aquisição que permeiam a alimentação até chegar às instituições de ensino. Assim como é considerada a individualidade de cada estudante frente às NAE e todos os cuidados no momento do preparo, demonstrando os motivos pelos quais o nutricionista garante que a alimentação será segura para ser consumida pelo estudante.

Cabe também ao nutricionista do PNAE esclarecer aos pais ou responsáveis as diretrizes do PNAE, as quais devem ser aplicáveis a todos os alimentos consumidos no ambiente escolar, independentemente de sua origem (CESAR et al., 2018). Ainda assim, se os pais ou responsáveis propuserem ofertar a alimentação especial diante de todas estas informaçoôes oferecidas, sugere-se que esta notificação seja realizada em reunião, de preferência com os gestores da SME e, se possível, com o Conselho de Alimentação Escolar (CAE), e também entregue por escrito, registrando a entrega. Após este procedimento, solicita-se a assinatura do termo de responsabilidade.

Em contrapartida, ao compreender que todo o alimento consumido no ambiente escolar se configura como alimentação escolar e está sob a responsabilidade da escola e da gestão (BRASIL, 2020; CESAR et al., 2018), esta medida não isenta a responsabilidade do nutricionista do PNAE frente a esta situação. Porém o documento assinado pode ser utilizado futuramente como uma prova legal de ciência dos fatos diante de alguma situação indesejada e, principalmente, do comprometimento dos pais ou responsáveis frente à alimentação especial.

\section{Orientação aos atores envolvidos com os estudantes com NAE}

Esta categoria é caracterizada pela apresentação dos principais atores envolvidos com estudantes que possuem NAE e a importância de manter um constante diálogo entre gestão, pais ou responsáveis e estudantes.

Quanto à realização da capacitação dos manipuladores de alimentos em relação às NAE, os participantes destacaram em suas respostas que a orientação destinada aos manipuladores de alimentos (merendeiras) é essencial para que o atendimento e a oferta da preparação sejam realizados conforme as condiçôes que cada uma das NAE exige, conforme pode-se constatar no depoimento a seguir: 


\begin{abstract}
A gestáo municipal apoia as mudanças nos cardápios, como capacitaçóes para as merendeiras e a inserção de alimentos diferenciados para esse público. Estamos sempre testando novas receitas, como as sem ovos, sem glúten e sem leite (nenhum dos nossos bolos e tortas salgadas possui leite) [P107].
\end{abstract}

A realização de capacitaçóes envolvendo os manipuladores de alimentos quanto às NAE foi relatada por 77,6\% ( $\mathrm{n}=104)$ dos participantes. Contudo, entre os municípios que capacitam os manipuladores de alimentos, 52,8\% ( $\mathrm{n}=55)$ não disponibilizam algum documento comprobatório.

Em relação à orientação sobre os cuidados com NAE destinada aos diretores/ coordenadores das instituiçôes de ensino e professores, os participantes também demonstraram em seus trechos de respostas que a gestão municipal possibilita a realização de orientaçôes sobre os processos burocráticos presentes em seu município, a fim de garantir o acesso do estudante à alimentação especial, assim como os cuidados específicos diante das patologias. Estas orientaçóes abrangem os profissionais da educação, atores fundamentais no processo do cuidado de saúde desses estudantes, por serem os profissionais que apresentam um vínculo maior durante o período escolar, conforme o trecho a seguir:

Constantemente procuramos informaçóes sobre os estudantes que necessitam de alimentação especial, as diretoras e professoras das escolas sempre orientam e nos enviam os laudos. $\mathrm{Na}$ escola, depois do conhecimento dos estudantes, todos são comprometidos com a alimentação dos mesmos [P79].

A importância dessa conduta profissional é evidenciada por 71,6\% (n=96) dos participantes ao realizarem esse tipo de orientação sobre os cuidados com NAE a estes profissionais da educação. Ressalta-se que essa conduta é de extrema importância, visto que nas instituiçóes de ensino sáo eles que têm um contato direto com os estudantes durante todas as atividades, o que inclui o momento da alimentação no refeitório. Além, disso, a maioria dos acidentes escolares com alimentos proibidos não ocorre dentro das cozinhas, e sim em outros espaços escolares.

A preocupação da gestão municipal em relação ao cuidado do estudante com NAE vai além do ambiente escolar, a fim de proporcionar um melhor cuidado referente ao estado de saúde dos estudantes por meio das orientaçóes destinadas aos pais ou responsáveis. Os resultados supracitados demonstram as diferentes maneiras de a gestáo municipal manter o contato e orientar os manipuladores de alimentos, profissionais da educação e pais ou responsáveis. 
O levantamento do atual cenário da NAE no âmbito escolar — assim como das medidas necessárias a serem determinadas e/ou utilizadas para que o estudante tenha acesso à alimentação adequada — torna-se essencial neste processo. Entre estas medidas pode-se citar a organização do serviço, estabelecimento de um meio de comunicação entre entidade executora e comunidade escolar, orientação destinada aos atores envolvidos e, principalmente, estabelecer um meio de identificação dos estudantes com NAE (COLARES, SORATTO, 2019).

Em se tratando da orientação destinada aos manipuladores de alimentos, a mesma deve ser supervisionada, e a capacitação precisa ser comprovada mediante apresentação de documentação, realizada periodicamente, e abordar temas quanto a higiene pessoal, manipulação higiênica dos alimentos e doenças transmitidas por alimentos (BRASIL, 2004). Em situaçóes onde as NAE se fazem presentes, os manipuladores de alimentos devem ser orientados também quanto às técnicas de preparo, receitas e adaptação de novas receitas, leitura dos rótulos, cuidados necessários e prevenção da contaminação cruzada (BRASIL, 2017).

Estudo realizado com nutricionistas responsáveis técnicos pela alimentação escolar municipal dos Estados de Minas Gerais e Espírito Santo (Brasil) demonstrou que $70 \%$ dos nutricionistas capacitavam os manipuladores de alimentos, permitindo a estes profissionais o conhecimento que envolve desde as boas práticas de manipulação até o aperfeiçoamento dos cuidados no preparo de alimentos nas instituiçôes de ensino (SOUZA et al., 2017). É importante destacar que a orientação relacionada às NAE não é limitada aos manipuladores de alimentos. É necessário compartilhar a informação sobre o direito à alimentação especial, ao acolhimento e ao atendimento destes estudantes com os pais ou responsáveis, assim como com o gestor escolar (diretor e coordenador), os professores e os integrantes do CAE, entre outros membros da comunidade (ROCHA et al., 2018). As condiçôes de NAE mais frequentes nas instituiçôes de ensino, por exemplo, podem ser abordadas nas formaçôes docentes continuadas, em rodas de conversa entre pais ou responsáveis e professores, permitindo a troca de vivências, aprendizado mútuo diante das patologias (BRASIL, 2017) e fortalecimento do objetivo do PNAE através de diversas ações de educação alimentar e nutricional (BRASIL, 2020; ROCHA et al., 2018).

Além da orientação presencial, a gestão municipal pode do mesmo modo estabelecer um mecanismo de orientação prévia sobre as NAE através de uma 
página de internet ou link de acesso no site da prefeitura destinado à alimentação escolar (BRASIL, 2017). Bem como disponibilizar algum material informativo no mural das instituiçóes de ensino contendo os requisitos necessários para obtenção da alimentação especial (COLARES; SORATTO, 2019), publicitar o cardápio utilizado nos murais estratégicos da escola, assim como a descrição das patologias, entre outras medidas, a fim de esclarecer sobre o direito dos estudantes a um cardápio especial (BRASIL, 2017). Assim, a tecnologia voltada à educação em saúde torna-se um instrumento didático que ultrapassa a simples oferta de informação, pois sensibiliza o indivíduo a realizar as mudanças de comportamento necessárias quanto ao estilo de vida, controle dos fatores de risco e adesão ao tratamento, seja ele medicamentoso ou não (MANIVA; CARVALHO; GOMES; CARVALHO; XIMENES; FREITAS, 2018).

\section{Dificuldades encontradas na gestáo do cuidado para a assistência aos estudantes com NAE}

Dentre as principais dificuldades encontradas pelos participantes para que a gestão realize o atendimento de todas as NAE em seus municípios, destaca-se a descrita no depoimento a seguir:

Tem sido intensa a busca para a aquisição dos gêneros alimentícios para o atendimento integral, mas sáo poucos os fornecedores interessados na venda destes produtos em nosso município devido às pequenas quantidades, à necessidade de realizaçáo de laudos e à entrega ponto a ponto [P67].

A oferta da alimentação especial que atenda todos os estudantes com NAE foi relatada por apenas 38\% ( $\mathrm{n}=51)$, e a falta de amparo a todas as NAE presentes nos municípios catarinenses justificou-se principalmente pela indisponibilidade de fornecedores, $23,1 \%(\mathrm{n}=31)$.

Além da indisponibilidade de produtos ou fornecedores, os participantes relataram a ausência de apresentação de laudo médico e/ou exame (tabela 1) como um fator decisivo na tomada de decisão da gestão quanto ao fornecimento da alimentação especial.

Nossa principal dificuldade é que nem sempre os médicos solicitam os exames básicos para constatar realmente a necessidade de alimentaçấo especial, muitas vezes pais e médicos simplesmente chegam a um consenso (nem sempre verídico) e acabamos tendo que atender [P93]. 
Em relação à disponibilidade de utensílios e/ou equipamentos exclusivos para a realização de algumas preparaçóes especiais (tabela 2), 63,4\% ( $\mathrm{n}=85)$ dos participantes sustentaram que no município onde atuam a gestão não oferece este tipo de segurança na preparação dos alimentos. O recurso humano insuficiente e a estrutura inadequada destinada ao atendimento das NAE de forma segura também foram citados como um dos problemas enfrentados pela gestão.

Quanto à presença de informaçóes on-line, ou seja, através de alguma página da SME ou link de acesso no site da prefeitura destinado à alimentação escolar que contenha orientaçôes sobre como a comunidade pode solicitar a alimentação especial aos estudantes matriculados na rede municipal, 99,3\% ( $\mathrm{n}=133)$ dos participantes relataram que em seu município não há esse tipo de mecanismo de informação.

A falha ou inexistência da comunicação dentro do setor de educação foi apontada pelos participantes como uma dificuldade enfrentada para que os estudantes recebam a alimentação especial. Quanto à presença de algum material informativo no mural da escola destinado à comunidade escolar sobre o direito ao cardápio especial, 92,5\% ( $\mathrm{n}=124)$ dos participantes relataram que não é disponibilizado este tipo de informação. E quanto à declaração de cancelamento da alimentação especial, $88,8 \%$ ( $\mathrm{n}=119)$ dos participantes responderam que não é disponibilizado esse tipo de declaração como ferramenta de comunicação entre responsáveis e a SME.

Devido à incompreensão dos atores envolvidos diante dos cuidados necessários em caso de NAE, os participantes relataram que o descumprimento das orientaçóes destinadas a todos os profissionais do setor de educação envolvidos com os estudantes portadores de NAE também foi apresentado como uma dificuldade enfrentada pelos participantes para que ocorra o atendimento.

Um aspecto importante apontado pelo presente estudo é o atendimento parcial das NAE presentes nos municípios. O não atendimento de algumas NAE corrobora os achados de outro estudo, que expressa que esse fato pode estar relacionado à falta de sensibilização e conhecimento dos envolvidos sobre as NAE, indisponibilidade de produtos e condiçóes de trabalho inadequadas (SOUZA et al., 2016). Ainda é fortalecido pela ausência de apresentação de laudo médico, alto custo dos produtos, indisponibilidade de utensílios e equipamentos exclusivos na utilizaçáo de algumas preparaçôes e a burocracia para a solicitação de alimentos especiais, impossibilitando o acesso e a garantia do direito à alimentação no ambiente escolar dos municípios catarinenses. 


\section{Facilidades encontradas na gestão do cuidado na assistência destinada aos estudantes com NAE}

Por fim, para a categoria "Facilidades encontradas na gestão do cuidado na assistência destinada aos estudantes com Necessidades Alimentares Especiais" descreve o posicionamento positivo de 93 nutricionistas quanto à gestão municipal para que as NAE sejam atendidas de acordo com as suas especificidades.

A garantia de atendimento das NAE é assegurada através do interesse e preocupação da gestão para que os estudantes recebam a alimentação especial, conforme o trecho a seguir:

Neste processo estão envolvidos os pais, o diretor, a nutricionista, o setor de compras, a merendeira, o CAE, o professor. Enfim, toda a comunidade escolar garantindo o melhor atendimento ao estudante portador de alguma necessidade alimentar especial [P68].

A facilidade encontrada no setor de compras e a parceria com o setor de licitação foram relatadas pelos participantes como um meio facilitador para a obtenção dos alimentos especiais. Outro aspecto importante apontado pelos participantes é a gestão conhecer a Lei 12.982 de 2014, a qual assegura a oferta de alimentos específicos aos estudantes com NAE, assim como o cardápio especial.

A maioria dos estudantes possui a mesma intolerância alimentar, o que facilita a compra
dos alimentos especiais. Outra facilidade é que a comunidade escolar já sabe do direito
dos estudantes em receber alimentação escolar, assim, esses estudantes com necessidades
são geralmente atendidos [P123].

Quando a gestão permite ao nutricionista decidir quais medidas serão necessárias, assim como participar do processo de compras para que ocorra o atendimento do estudante com NAE, segundo os participantes, a aquisição dos alimentos especiais acaba sendo facilitada devido à autonomia do nutricionista.

Os participantes afirmam que a gestão garante o atendimento dos estudantes com NAE por reconhecer o direito à alimentação especial, compreender a importância da manutenção e melhora do estado de saúde dos estudantes, ofertar os alimentos especiais, apresentar profissionais comprometidos em suas equipes, bem como a confiança atribuída ao nutricionista do PNAE diante de qualquer tomada de decisão.

A responsabilidade legal pela gestão e execução do PNAE em nível local é atribuída às SMEs, que, para tanto, precisam controlar, planejar, estruturar, organizar, avaliar e executar a maioria dos serviços voltados à alimentação escolar, tendo profissionais específicos e competentes para a realização desse trabalho (SILVA et al., 2016). 
Ao compreender a Lei no 12.982 e a necessidade de realização de uma gestão do cuidado municipal efetiva, os princípios do Sistema Único de Saúde relativos à universalidade e, principalmente, à equidade no atendimento aos estudantes com NAE, se aproximam do objetivo em assegurar a oferta da alimentação escolar adequada a esses estudantes (BRASIL, 2014). Ainda, garante como um cardápio individualizado que atenda às recomendaçôes médicas e nutricionais a avaliação do estado nutricional e demandas nutricionais diferenciadas, aspectos que implementam o princípio da integralidade da atenção (BRASIL, 2020; 2014). Ressalta-se que, em sua maioria, uma das maneiras de prevenção e/ou tratamento das NAE ocorre através de uma alimentação adequada, seja por meio de uma restrição e/ou prescrição de um determinado alimento, a essa condição de saúde, a fim de amenizar os sintomas e, consequentemente, melhorar o estado de saúde do indivíduo (SBD, 2016; SBC, 2017).

Considerando essa característica sobre a influência da alimentação na melhora do estado de saúde, a gestão do cuidado municipal, por meio da alimentação escolar, adota o compromisso com o DHAA ao ofertar uma alimentação especial individualizada, que atenda às necessidades nutricionais, proporcionando um bom desenvolvimento psicossocial e cognitivo (SOUZA et al., 2016).

\section{Considerações finais}

O serviço de assistência nutricional concedido aos estudantes com NAE demonstrou que a gestão do cuidado no âmbito municipal necessita estar preparada para realizar o atendimento, independentemente do momento em que os agravos sejam apresentados na rede municipal de ensino, e que seja amparada por profissionais capacitados e em quantidade compatível com a demanda, capazes de compreender o funcionamento do PNAE e suas particularidades, visto esses serem aspectos frágeis na maioria dos municípios. Assim como a importância deste tipo de atendimento, a fim de evitar agravos futuros e, consequentemente, uma redução na demanda no setor de saúde proporcionando o DHAA a todos os estudantes com NAE.

Por fim, o serviço de assistência nutricional no Estado de Santa Catarina possui mecanismos de gestáo diversos, atendendo em grande parte às necessidades dos estudantes com NAE, mas ainda apresenta algumas fragilidades que dificultam a efetivação da assistência integral aos estudantes com necessidades alimentares especiais. 
A principal limitação do estudo foi no tocante ao enfoque quantitativo, restringindo a representatividade, que foi consideravelmente afetada pelo desinteresse em participação da pesquisa por parte de 113 nutricionistas responsáveis pela alimentação escolar dos municípios do Estado de Santa Catarina. Isso poderia em tese indicar outros resultados; no entanto, cabe reforçar que os dados quantitativos subsidiaram os achados qualitativos, os quais foram amplamente saturados. ${ }^{1}$

\section{Referências}

BRASIL. Casa Civil. Decreto $n^{\circ}$ 7.892, de 23 de janeiro de 2013. Regulamenta o Sistema de Registro de Preços previsto no art. 15 da Lei ne 8.666, de 21 de junho de 1993. Brasília, 2013b. Disponível em: http://www.planalto.gov.br/ccivil_03/_ato2011-2014/2013/decreto/d7892.htm. Acesso em: nov.2018.

. Casa Civil. Lei n $n^{\circ}$ 10.520, de 17 de julho de 2002. Institui, no âmbito da União, Estados, Distrito Federal e Municípios, nos termos do art. 37, inciso XXI, da Constituição Federal, modalidade de licitação denominada pregão, para aquisição de bens e serviços comuns, e dá outras providências. Brasília, 2002. Disponível em: http://www.planalto.gov.br/ccivil_03/ Leis/2002/L10520.htm. Acesso em: 10 Dez. 2017.

. Casa Civil. Lei no 8.666, de 21 de junho de 1993. Regulamenta o art. 37, inciso XXI, da Constituição Federal, institui normas para licitaçôes e contratos da Administração Pública e dá outras providências. 1993. Disponível em: http://www.planalto.gov.br/ccivil_03/ Leis/L8666cons.htm. Acesso em: 8 Dez. 2017.

. Lei no 11.947 , de 16 de junho de 2009. Dispôe sobre o atendimento da alimentação escolar e do Programa Dinheiro Direto na Escola aos alunos da educação básica. Diário Oficial da União, n. 113, 17 jun. 2009. Disponível em: http://www.planalto.gov.br/ccivil_03/_ato20072010/2009/Lei/l11947.htm. Acesso em: 10 dez. 2017.

. Lei $n^{\circ}$ 12.982, de 28 de maio de 2014. Altera a Lei no 11.947, de 16 de junho de 2009, para determinar o provimento de alimentação escolar adequada aos alunos portadores de estado ou de condição de saúde específica. 2014. Disponível em: http://www2.camara.leg.br/legin/ fed/lei/2014/lei-12982-28-maio-2014-778811-publicacaooriginal-144230-pl.html. Acesso em: 10 jan. 2018.

- Ministério da Saúde. Agência Nacional de Vigilância Sanitária. Resolução $R D C n^{\circ}$ 26, de 2 de julho de 2015. Dispóe sobre os requisitos para rotulagem obrigatória dos principais alimentos que causam alergias alimentares. 2015. Disponível em: http://portal.anvisa.gov.br/ documents/10181/2694583/RDC_26_2015_.pdf/b0a1e89b-e23d-452f-b029-a7bea26a698c. Acesso em: 16 nov. 2018. 
Ministério da Saúde. Política Nacional de Alimentação e Nutrição. Brasília, 2013a. Disponível em: http://bvsms.saude.gov.br/bvs/publicacoes/politica_nacional_alimentacao_ nutricao.pdf. Acesso em: 10 jan. 2018.

- Ministério da Saúde. Programa Nacional de Alimentação Escolar. Caderno de referência sobre alimentação escolar para estudantes com necessidades alimentares especiais. Brasília: FNDE, 2017. 65 p. Disponível em: . Acesso em: 16 jan. 2018.

. Ministério da Saúde. Resolução no 6, de 8 de maio de 2020. Dispóe sobre o atendimento da alimentação escolar aos alunos da educação básica no âmbito do Programa Nacional de Alimentação Escolar-PNAE. 2020. Disponível em: https://www.fnde.gov.br/index.php/acessoa-informacao/institucional/legislacao/item/13511-resolu\%C3\%A7\%C3\%A3o-n\%C2\%BA-6,de-08-de-maio-de-2020. Acesso em: 28 mai. 2020.

. Ministério da Saúde. Resolução-RDC n 216, de 15 de setembro de 2004. Dispóe sobre Regulamento Técnico de Boas Práticas para Serviços deAlimentação. 2004. Disponível em: http:// portal.anvisa.gov.br/documents/33916/388704/RESOLU\%25C3\%2587\%25C3\%2583O-RD C\%2BN\%2B216\%2BDE\%2B15\%2BDE\%2BSETEMBRO\%2BDE\%2B2004.pdf/23701496925d-4d4d-99aa-9d479b316c4b. Acesso em: 17 nov. 2018.

CESAR, J. T. et al. Alimentação Escolar no Brasil e Estados Unidos: uma revisão integrativa. Ciênc. saúde coletiva, Rio de Janeiro, v. 23, n. 3, p. 991-1007, mar. 2018. Disponível em: http:// www.scielo.br/scielo.php?script=sci_arttext $\&$ pid $=$ S1413-81232018000300991\&lng=en\&nrm= iso. Acesso em: 11 nov. 2018.

COLARES, S. S.; SORATTO, J. Itinerários para atenção integral aos alunos com necessidades alimentares especiais. Criciúma: Ed. do Autor, 2019. 18p. Disponível em: http://repositorio. unesc.net/handle/1/6716. Acesso em: 6 maio 2019.

CONSELHO Federal de Nutricionistas. Resolução CFN no 599/2018. Aprova o código de ética e de conduta do nutricionista e dá outras providências. Brasília: CFN, 2018. Disponível em: http:// www.cfn.org.br/wp-content/uploads/resolucoes/Res_599_2018.htm. Acesso em: 17 nov. 2018.

CORREA, R. S. et al. Atuação do Nutricionista no Programa Nacional de Alimentaçáo Escolar na Região Sul do Brasil. Ciênc. saúde coletiva, Rio de Janeiro, v. 22, n. 2, p. 563574, fev. 2017. Disponível em: http://www.scielo.br/scielo.php?script=sci_arttext\&pid=S1413$81232017000200563 \& \operatorname{lng}=$ en\&nrm=iso. Acesso em: 18 nov. 2018.

CRESWELL, J. W. Projeto de pesquisa: métodos qualitativo, quantitativo e misto. 3 ed. Porto Alegre: Artmed; 2010.

MANIVA, S. J. C. F. et al. Tecnologias educativas para educação em saúde no acidente vascular cerebral: revisão integrativa. Rev. Bras. Enferm., Brasília, v. 71, supl. 4, p. 17241731, 2018. Disponível em: http://www.scielo.br/scielo.php?script=sci_arttext\&pid=S0034$71672018001001724 \& \operatorname{lng}=$ pt\&nrm=iso. Acesso em: 23 nov. 2018. 
MATTAR, R.; MAZO, D. F. C. Intolerância à lactose: mudança de paradigmas com a biologia molecular. Rev. Assoc. Med. Bras. São Paulo, v. 56, n. 2, p. 230-236, 2010. Disponível em: http://www.scielo.br/scielo.php?script=sci_arttext\&pid=S0104-42302010000200025\&lng=en \&nrm=iso. Acesso em: 20 fev. 2018.

ORGANIZAÇÓES DAS NAÇÓES UNIDAS. Comentário Geral n. 12 - O Direito Humano a Alimentação Adequada (art. 11), 1999. Disponível em: http://pfdc.pgr.mpf.mp.br/atuacao-econteudos-de-apoio/publicacoes/alimentacao-adequada/Comentario\%20Geral\%20No\%2012. pdf.Acesso em: 15 nov. 2017.

ROCHA, N. P. R et al. Análise do programa nacional de alimentação escolar no município de Viçosa, MG, Brasil. Rev. Saúde Pública. São Paulo, v. 52, 2018. Disponível em: http://www.rsp.fsp. usp.br/artigo/analise-do-programa-nacional-de-alimentacao-escolar-no-municipio-de-vicosamg-brasil/. Acesso em: 14 fev. 2019. https://doi.org/10.11606/S1518-8787.2018052007090.

SANTOS, J. L. G et al. Integração entre dados quantitativos e qualitativos em uma pesquisa de métodos mistos. Texto contexto - enferm., Florianópolis, v. 26, n. 3, 2017. Disponível em: http:// www.scielo.br/scielo.php?script=sci_arttext\&pid=S0104-07072017000300330\&lng=en\&nrm =iso. Acesso em: 4 jun 2018. http://dx.doi.org/10.1590/0104-07072017001590016.

SILVA, L. A. A. et al. Gestão da atenção à saúde de usuários com doenças crônicas e degenerativas. Saúde (Santa Maria), v. 42, n. 1, p. 67-74, jan./jun. 2016. Disponível em: https:// periodicos.ufsm.br/revistasaude/article/view/19558/pdf. Acesso em: 1 dez 2018. http://dx.doi. org/10.5902/2236583419558.

SOCIEDADE BRASILEIRA DE CARDIOLOGIA (SBC). Atualização da Diretriz Brasileira de Dislipidemias e Prevenção da Aterosclerose - 2017. Rio de Janeiro: SBC, v. 109, n. 2, supl. 1, ago. 2017. Disponível em: http://publicacoes.cardiol.br/2014/diretrizes/2017/02_DIRETRIZ_ DE_DISLIPIDEMIAS.pdf. Acesso em: 5 mar. 2018.

SOCIEDADE BRASILEIRA DE DIABETES (SBD). Diretrizes da Sociedade Brasileira de Diabetes 2015-2016. São Paulo: AC Farmacêutica, 2016. Disponível em: http://www.diabetes. org.br/profissionais/images/docs/DIRETRIZES-SBD-2015-2016.pdf. Acesso em: 5 mar. 2018.

SORATTO, J.; PIRES, D. E. P.; FRIESE, S. Thematic content analysis using ATLAS.ti software: Potentialities for researchs in health. Rev. Bras. Enferm., Brasília, v. 73, n. 3, 2020. Disponível em: http://www.scielo.br/scielo.php?script=sci_arttext\&pid=S0034-71672020000300403\&lng =en\&nrm=iso. Acesso em: 28 maio 2020.

SOUZA, A. H. W. et al. Alimentação escolar e direitos humanos: um enfoque nas necessidades alimentares especiais. Rev. História Helikon, Curitiba, v. 3, n. 6, p. 105-124, 2o sem. 2016. Disponível em: https:/www.researchgate.net/publication/317825724_Alimentacao_Escolar_e_ Direitos_Humanos_um_Enfoque_nas_Necessidades_Alimentares_Especiais_School_ Feeding_and_Human_Rights_A_Focus_on_Special_Dietary_Needs. Acesso em: 6 fev. 2018. 
SOUZA, C. B. et al. Prevalência de Hipertensão em Crianças de Escolas Públicas. International Journal of Cardiovascular Sciences, Rio de Janeiro, v. 30, n. 1, p. 42-51, fev. 2017. Disponível em: http://www.scielo.br/scielo.php?script=sci_arttext\&pid=S2359-56472017000100042\&lng=en \&nrm=iso. Acesso em: 26 fev. 2019.

VASCONCELOS, F. A. G. et al. (Orgs.). Manual de orientaçâo sobre a alimentaçâo escolar para portadores de diabetes, hipertensão, doença celíaca, fenilcetonúria e intolerância a lactose. 2. ed. Brasília: PNAE: CECANE-SC, 2012. 54 p.

\section{Nota}

${ }^{1}$ S. da S. Colares participou da concepção, planejamento, análise, interpretação e redação do trabalho. F. Ferraz participou da análise dos dados, redação do artigo. I. D. S. Perry participou da análise dos dados, interpretação, redação do artigo. J. Soratto orientou a pesquisa e participou da concepçáo, planejamento, análise, interpretação e redação do trabalho. 


\section{Abstract}

Care management of students with special food needs linked to the National School Food Program

To analyze the care management mechanisms aimed at students with Special Food Needs (SFN) linked to the Municipal Education Secretariats of the state of Santa Catarina. It is a study of mixed methods, with a concomitant incorporated strategy, carried out with 134 nutritionists who assist students with SFN. A questionnaire sent by electronic mail was used as a data collection instrument, being analyzed through thematic content analysis and descriptive statistics. The results indicated that the medical certificate or report for offering special food was the main supporting document; the public auction was the means of obtaining special foods; food handlers predominated in receiving guidance regarding SFN; lack of products and suppliers was indicated as difficulties, and guarantee of service highlighted as ease in the management of SFN; as for the management characteristics, the absence of a request for a technical sheet $(79.9 \%)$, special food supply (62\%), information material (92.5\%) and availability of utensils (63.4\%) stand out. The nutritional assistance in cities has different management mechanisms, which meet the needs of students with SFN, but still have some weaknesses that hinder the implementation of comprehensive care.

> Keywords: health management; nutrition programs and policies; school feeding. 